\title{
MODELO DE CRESCIMENTO POPULACIONAL COM DINÂMICA TEMPORAL FRACIONÁRIA
}

\author{
AUTOR: MILLER CALIXTO ALMEIDA \\ CO-AUTOR/ORIENTADOR: DANIELLE OLIVEIRA COSTA SANTOS
}

\begin{abstract}
Resumo: A modelagem numérica vem norteando pesquisadores de diversas áreas, se mostrando uma das principais ferramentas para a compreensão de fenômenos. Associada aos modelos de crescimento populacional pode-se estimar a proliferação de populações, possibilitando conjecturar vários cenários, para melhor avaliação das medidas a serem adotadas. O presente trabalho teve como objetivo a análise e desenvolvimento de modelos de crescimento populacional de espécies com dinâmica temporal fracionária, via formalismo de Grunwald-Letnikov. Com implementação dos códigos em C\#, foram testados e analisados os modelos de crescimento populacional de Malthus e Verhulst, através do método de Euler, aplicando posteriormente a derivada fracionária de Grunwald-Letnikov. Os principais resultados encontrados para valores de $h: 10^{-1}, 10^{-2}, 10^{-3}$, mantendo alpha fixo inicialmente em 0.2 , consecutivamente 0.5 ,e 0.8 foi que, quando $\mathrm{h}$ decresce as curvas tendem a apresentar resultados mais próximos do comportamento real para o problema modelado, e para alpha próximos de 1.0 teremos curvas mais inclinadas com os maiores valores para $y(t)$. Esses resultados mostram que para o passo (h) mais distante de zero, gera-se aproximações com erro numérico maior, e para alpha próximos de 0.0 as curvas tendem a saturar para valores menores de tempo.
\end{abstract}

Palavras-chave: Crescimento populacional, modelagem numérica, derivada fracionária. 